\title{
Comparative Analysis of Inkjet Printer Inks Extracted from Printed Documents by FT-IR Spectrophotometry
}

\author{
Rashmi Sharma ${ }^{1}$, Kavita Goyal ${ }^{2}$, Amit Chattree ${ }^{3}$, T.R.Baggi ${ }^{4}$, A.K.Gupta ${ }^{5}$ \\ 1. Senior Research Fellow, Central Forensic Science Laboratory, Ramanthapur, Hyderabad, A.P.500013, \\ India. \\ 2. Senior Scientific Officer, Forensic Science Laboratory, Rohini, Delhi-110085, India. \\ 3. Head, Department of Chemistry, SHIATS, Allahabad, U.P.-211007, India. \\ 4. Academic Coordinator, Forensic Science Unit, Department of Chemistry, University College of Science, \\ Osmania University, Hyderabad, A.P. 500007, India. \\ 5. Head, Department of Forensic Science, SHIATS, Allahabad, U.P.-211007, India.
}

\begin{abstract}
Primary coloured inks i.e. Cyan, Magenta, Yellow, and Black used in inkjet printers were extracted from the printed document and analyzed in order to identify the possible functional groups using Infrared (IR) spectroscopic technique. Experiments were conducted on the all four primary inks and the results are presented. The technique can provide valuable information if an admitted sample is provided for comparison with the suspect printed document.
\end{abstract}

Keywords: Functional Group, Inkjet Printing, Infrared Spectroscopy, Printer, Printed Document.

\section{Introduction}

Determination of authenticity of a document is based on many factors. Characterization of writing/printing instruments used to produce the document such as ink; paper etc may be a leading step in the investigation. Many instrumental analytical techniques are available to determine the actual composition of dyes and other compounds present in inkjet printer inks. The IR technique is one of the techniques which can provides important information about the commercially available printer inks (Yuen et al, 2005). IR spectroscopy deals with the infra red region of the electromagnetic spectrum. The IR portion of the electromagnetic spectrum is usually divided into three regions; the near-IR (approximately $14000-4000 \mathrm{~cm}^{-1}$ ), mid-IR $\left(4000-400 \mathrm{~cm}^{-1}\right)$ and far- infrared $\left(400-10 \mathrm{~cm}^{-1}\right)$. The near-IR can excite overtone or harmonic vibrations, the mid-infrared may be used to study the fundamental vibrations and associated rotationalvibrational structure whereas the far-infrared has low energy and may be used for rotational spectroscopy. IR spectroscopy is based upon the ability of certain compounds to absorb radiation by interaction of IR radiation with the molecular bonds of the sample. Absorption occurs when the molecular bond has a vibrational frequency equal to the IR radiation. The wavelengths at which a measured absorption occurs correspond to specific functional groups. This information can be interpreted to characterize the compounds.

Fourier Transform Infrared Spectroscopy (FTIR) is used to obtain an infrared spectrum of a solid, liquid or gas. In the Fourier Transform instrument the whole wavelength range is measured at once and then a transmittance or absorbance spectrum is generated with the help of a computer. Analysis of the position, shape and intensity of peaks in the spectrum reveals details about the molecular structure of the sample. A simple glass tube with length of 5 to $10 \mathrm{~cm}$ equipped with infrared windows at the both ends of the tube can be used for concentrations down to several hundred ppm. Sample gas concentrations well below ppm can be measured with a White's cell in which the infrared light is guided with mirrors to travel through the gas. Liquid samples can be sandwiched between two plates of highly polished transparent sodium chloride, potassium bromide or calcium fluoride. These plates are transparent to the infrared light.

Solid samples can be prepared in a variety of ways such as by finely mixing the fine powder sample with an oily mulling agent (usually Nujol) in a marble or agate mortar, with a pestle. A thin film of the mull is smeared onto salt plates and measured. The second method is to grind a quantity of the sample with potassium bromide finely. This powder mixture is then pressed in a mechanical press to form a translucent pellet through which the beam of the spectrometer can pass. A third technique is the "cast film" technique mainly used for polymeric materials and most suitable for qualititative analysis. The sample is first dissolved in a suitable, non hygroscopic solvent. A drop of this solution is deposited on surface of $\mathrm{KBr}$ or $\mathrm{NaCl}$ cell. The solution is then evaporated to dryness and the film formed on the cell is analyzed directly. The final method is to use microtomy to cut a thin $(20-100 \mu \mathrm{m})$ film from a solid sample. IR technique can provide valuable information about the chemical composition of a material (Kan, et al., 2000; Wen, 2004; Huang, 2004) with convenient sample analysis. 
As little work has been done on the analysis and comparison of inkjet printer ink by this technique, in the present work an attempt has been made to examine the ink of ink jet printer extracted from printed documents by preparing the $\mathrm{KBr}$ pellet and to generate characteristic IR spectra.

\section{Experimental}

\subsection{Sampling}

Thirty two (32) coloured printouts each containing four rectangular blocks of cyan, magenta, yellow and black colour were printed from inkjet printers of four leading manufacturers. White paper of A4 size from same company was used to take all samples. The colours were selected by following RGB model. All four printed colour i.e. cyan, magenta, yellow and black from each printout were extracted and analyzed. A total of $32 \times 4=128$ samples were analyzed and interpreted.

The four leading brands were marked as A, B, C and D and their different models were marked as 1, 2, 3 and so on. The samples were given marking as $1,2,3,4,5,6,7,8,9,10,11,26,27,28,30,31,32$ for different models of brand ' $\mathrm{A}$ ' , 16,18,19,23,24,29 for different models of brand 'B', 12,13,20,21 for different models of brand 'C' and $14,15,17,22,25$ for different models of brand ' $D$ '.

\subsection{Separation of ink from printed Document}

A coloured squared block of constant area was taken from the sample document and cut into small pieces. The pieces of paper were then transferred to $15 \mathrm{~mL}$ beaker and titurated with $10 \mathrm{ml}$ of methanol. The sample was then allowed to be extracted at room temperature with intermittent shaking. The methanol extract was then transferred to $10 \mathrm{ml}$ volumetric flasks after filtering through a Whatman No.1 filter paper. The extract was made up to $10 \mathrm{ml}$.

The same procedure was followed for all samples for cyan, magenta, yellow and black. In order to avoid any interference and to record the response of matrix i.e. paper and the reagent i.e. methanol towards IR, the blank samples of matrix and reagent were also prepared following the same procedure.

\subsection{Preparing Pellet for Scanning}

Two (2) ml of methanolic solution was taken in a china dish and evaporated at room temperature to dryness and heated briefly in an oven. The residue was scratched from the walls of china dish and mixed intimately with dry $\mathrm{KBr}$. After this process pellets were prepared by using a pellet maker. The same procedure was followed for all samples of Cyan, Magenta, Yellow and Black Colour.

\subsection{Scanning of Samples}

A FT-IR Spectrometer from Perkin Elmer model Spectrum GX with attached Multiscope IR Microscope, Mercury Cadmium Telluride (MCT) detector and computer system with spectrum software was utilized to scan the samples. A resolution of $8 \mathrm{~cm}^{-1}$ and gain of 4 were set for the experiments. 32 scans were averaged for each sample. The Pellets were then scanned in the IR beam and the spectrum was recorded in the range of 3500 to 400 wave number ${ }^{-1} \mathrm{~cm}$ in transmittance mode.

The extract from the blank paper, used for the sampling, was also recorded as background spectrum. After scanning of pellets the spectra were normalized in order to reduce the noise. The reproducibility of the results was checked 3 times on 3 different days at an interval of 5 days. The samples were prepared by following the same procedure every time and scanned keeping the same settings.

\section{Results And Discussion}

The analysis of IR spectra was carried out by referring the table for regions of the Infrared spectrum for preliminary analysis (Lambert et al. 1998). The different coloured samples of computer printing inks from the document were extracted from the documents (causing minimum damage of the document) and analyzed after preparing $\mathrm{KBr}$ pellets. The IR spectra obtained show highly characteristic absorption bands depending upon the compositions of the printer inks. In the rapidly changing technology in the computer printing inks based on various physicochemical parameters such as fastness, stability, toxicity and appearance etc large number of ingredients (dyes, resins, solvents, surfactants, biocides, corrosion inhibitors, shear thinning agents, lubricants, etc) which are constantly being changed, reviewed and introduced lot of inter-manufacturer variations can be expected. These minute variations help a document examiner to compare and discriminate between large numbers of computer printing inks.

In the following pages comparative spectra of five samples of black computer printer inks obtained during this study are presented. After the analysis it can be generalized that every printer ink batch exhibits characteristic IR spectra whereas different brands of ink cartridge exhibit different characteristic IR spectra. Note the similar spectra for all the sample with a negligible variation. Some common ingredients in different brands give similar IR spectral bands for those components. Two inks extracts from the same cartridge on the 
same paper exhibit similar IR spectra. Two inks extracts from the different cartridges of the same brands on the same paper exhibit broader similarities but subtle differences. Two ink extracts from different cartridges of different brands on the same paper exhibit marked differences. When certain admitted/specimen colour printouts are analyzed for comparison with the questioned print outs by the proposed technique it was possible to identify the printer inks by processes of exclusion and inclusion.

The similar work was carried out for Cyan, Magenta and Yellow colored printed inkjet inks and similarly we can find out the possible functional group and compound present in ink. The results obtained were found suitable for the comparison of printed ink of various brands. The difference between various samples of ink can be seen by observing at the intensity of main peak, the pattern of each spectrum and the absence or presence of some characteristic bands. It is possible to examine inks from printed documents. The technique is rapid and sample requirement is very small. The method is simple and provides rapid, reproducible method to differentiate inks using negligibly small portion from an insignificant area of the document.

Table 2: Possible functional groups and compounds present in Black coloured inks

\begin{tabular}{|c|c|c|}
\hline $\operatorname{Region}\left(\mathrm{cm}^{-1}\right)$ & Group & Possible Compounds Present \\
\hline $3700-3100$ & $\begin{array}{l}-\mathrm{OH} \\
-\mathrm{NH} \\
\equiv \mathrm{C}-\mathrm{H}\end{array}$ & $\begin{array}{l}\text { Alcohol, aldehyde, carboxylic acids } \\
\text { Amides, amines } \\
\text { Alkynes }\end{array}$ \\
\hline $3100-3000$ & $\begin{array}{l}=\mathrm{C}-\mathrm{H} \\
-\mathrm{CH}_{2} \text { or }-\mathrm{CH}=\mathrm{CH}-\end{array}$ & $\begin{array}{l}\text { Aromatic compounds } \\
\text { Alkenes or unsaturated rings } \\
\end{array}$ \\
\hline $3000-2800$ & $\mathrm{CH},-\mathrm{CH}_{2-},-\mathrm{CH} 3$ & Aliphatic groups \\
\hline $2400-2000$ & $\begin{array}{l}-\mathrm{C} \equiv \mathrm{N} \\
-\mathrm{N}=\mathrm{N}^{+}=\mathrm{N}^{-} \\
-\mathrm{C} \equiv \mathrm{C}-\end{array}$ & $\begin{array}{l}\text { Nitriles } \\
\text { Azides } \\
\text { Alkynes }\end{array}$ \\
\hline $1870-1650$ & $\mathrm{C}=\mathrm{O}$ & $\begin{array}{l}\text { Acid halides, aldehydes, amides, amino acids, anhydrides, carboxylic acids, } \\
\text { esters, ketones, lactams, lactones, quinines }\end{array}$ \\
\hline $1650-1550$ & $\mathrm{C}=\mathrm{C}, \mathrm{C}=\mathrm{N}, \mathrm{NH}$ & $\begin{array}{l}\text { Unsaturated aliphatics, aromatics, unsaturated heterocycles, amides, amines, } \\
\text { amino acids }\end{array}$ \\
\hline $1550-1300$ & $\begin{array}{l}\mathrm{NO}_{2} \\
\mathrm{CH}_{3} \text { and } \mathrm{CH}_{2}\end{array}$ & $\begin{array}{l}\text { Nitro compound } \\
\text { Alkanes, Alkenes,etc }\end{array}$ \\
\hline $1300-1000$ & $\begin{array}{l}\mathrm{C}-\mathrm{O}-\mathrm{C} \text { and } \mathrm{C}-\mathrm{OH} \\
\mathrm{S}=\mathrm{O}, \mathrm{P}=\mathrm{O}, \mathrm{C}-\mathrm{F}\end{array}$ & $\begin{array}{l}\text { Ethers, alcohols, sugars } \\
\text { Sulphur, phosphorus, and fluorine compounds }\end{array}$ \\
\hline $1100-800$ & Si-O and $\mathrm{P}-\mathrm{O}$ & Organosilicon and phosphorus compounds \\
\hline $1000-650$ & $\begin{array}{l}=\mathrm{C}-\mathrm{H} \\
-\mathrm{NH}\end{array}$ & $\begin{array}{l}\text { Alkenes and aromatic compounds } \\
\text { Aliphatic amines }\end{array}$ \\
\hline $800-400$ & $\begin{array}{l}\text { C-halogen } \\
\text { Aromatic rings }\end{array}$ & $\begin{array}{l}\text { Halogen compounds } \\
\text { Aromatic compounds }\end{array}$ \\
\hline
\end{tabular}

The analysis of IR spectrum for single bonds to hydrogen, for double bonds $\mathrm{C}=\mathrm{O}, \mathrm{C}=\mathrm{N}, \mathrm{C}=\mathrm{C}, \mathrm{N}=\mathrm{N}$ etc, for aromatic compounds that exhibit characteristic bands in several regions and in the fingerprint region the bands show:

(i) H-bonded -OH with - O- $\mathrm{H}$ stretching at alcohol was observed for sample no.1-5, 7-23, 25-32. at $3300-2500 \mathrm{~cm}^{-1}$.

(ii) H-bonded -OH with - O- $\mathrm{H}$ bending at $1440-1395 \mathrm{~cm}^{-1}$ were present in sample no. 8,10,11,14,15,19,22 26,32 and 950-910 $\mathrm{cm}^{-1}$ in Sample no. 1-3,8,11,15,16,22,23,25,28,32.

(iii) For Aldehyde, carboxylic acids and alkynes the bands were present at $3600-3200 \mathrm{~cm}^{-1}$ and observed in Sample no. 1-8, 10-11, 15, 16, 18-19, 22, 24-26, 28-29, 32 .

(iv) $=\mathrm{N}-\mathrm{H}$ with $\mathrm{N}-\mathrm{H}$ stretching at $3500-3300 \mathrm{~cm}^{-1}$ was observed in $1-6,8,10-11,15,16,18-19,22,24-26$, $29,32$.

(v) $-\mathrm{NH}_{2}$ with $\mathrm{N}-\mathrm{H}$ bending at $1650-1560 \mathrm{~cm}^{-1}$ were observed in sample no. 1-16,20-32 were absent in all the other samples.

(vi) $=\mathrm{CH}$ with saturated $\mathrm{C}$ - $\mathrm{H}$ stretching at $3000-2800 \mathrm{~cm}^{-1}$ for aliphatic compounds were present in Sample no. $1-13,16,19-23,25,27-30,32$.

(vii) $=\mathrm{CH}$ with $\mathrm{C}-\mathrm{H}$ bending at $1000-650 \mathrm{~cm}-1$ for Alkenes, Aromatic compounds present in Sample no.1$8,10-12,16,19-20,22-30-32$.

(viii) For double bonds $\mathrm{C}=\mathrm{O}$ at

(a) $1740-1720 \mathrm{~cm}^{-1}$ for Aldehydes observed in sample no. 1,2,3,5,7,8,10,11,12,15,16,20,26,28,32.

(b) $1750-1730 \mathrm{~cm}^{-1}$ for Esters present in sample no.1-12, 16, 20, 26, 28,30,32.

(c) $1680-1630 \mathrm{~cm}^{-1}$ for Amides observed in sample no.1-11, 16, 22-28, 30, 32 . 
(ix) Conjugated cyclic system of $\mathrm{C}=\mathrm{N}$ with $\mathrm{C}=\mathrm{N}$ stretching at $1690-1640 \mathrm{~cm}^{-1}$ for Imines \& Oximes observed in 1-11,16-18,22-25,27-30,32.

(x) $\mathrm{C}=\mathrm{C}$ conjugated with aromatic ring with $\mathrm{C}=\mathrm{C}$ stretching at $\sim 1625 \mathrm{~cm}^{-1}$ observed in $12,14,15,16,19,26,27$.

(xi) $\quad \mathrm{N}=\mathrm{N}$ stretching at $1500-1400 \mathrm{~cm}^{-1}$ were observed in sample no.1-11,13,15-19,21-30,32.

(xii) $\mathrm{C}-\mathrm{O}-\mathrm{C}, \mathrm{C}-\mathrm{OH}, \mathrm{S}=\mathrm{O}, \mathrm{P}=\mathrm{O}, \mathrm{C}-\mathrm{F}$ at $1300-1000 \mathrm{~cm}-1$ for ethers, alcohols, Sulfur, phosphorus and fluorine compounds were present in sample no.1-12,14-16,18-20,22-30,32.

(xiii) $\mathrm{O}$ bonded $\mathrm{Si}$ and $\mathrm{P}$ for Organosilicon and phosphorus compounds at $1100-800 \mathrm{~cm}^{-1}$ were observed for sample no.1-7, 12-15, 17-18, 20-25, and 27-30.

(xiv) C-halogen aromatic rings at $800-400 \mathrm{~cm}^{-1}$ for halogen and aromatic compounds were observed as several weak bands in all samples.

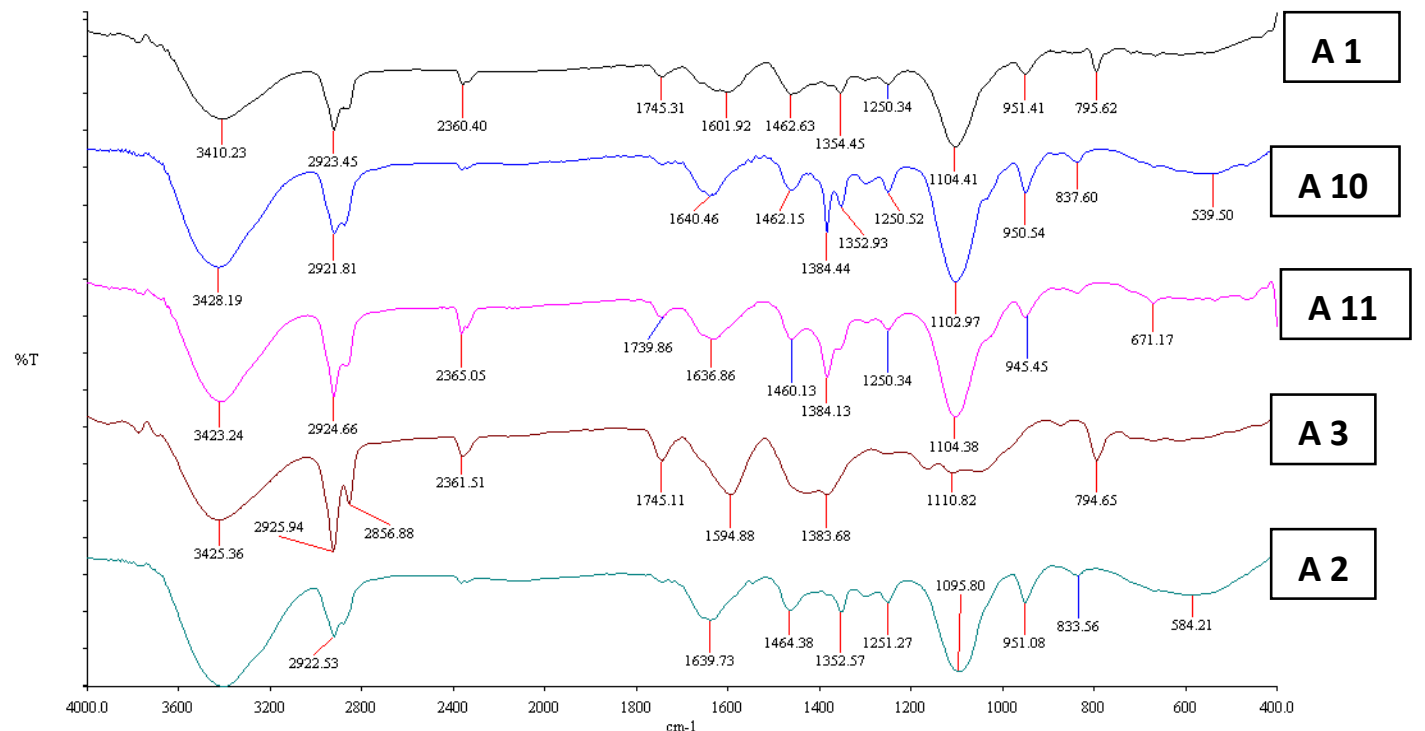

Figure:-1 FT-IR comparitive spectra of five samples of black colour ink for brand ' $A$ '.

There is a need of the hour to develop tools based on the pattern recognition or image processing techniques. Djozen et al, 2008 developed software in MATLAB tool based on the intensity profile of RGB characteristics for the discrimination of pen inks after TLC analysis. Such tools can also successfully be employed for the examination of printing inks. Besides the other tools should be developed based on the pattern recognition techniques and utilize for the quick comparison of ink from the forensic point of view. Fig 2 shows the typical graphical representation of spectra obtained after FT-IR analysis for all samples of cyan ink which shows clear visible differences between the inks of different brands. The discrimination and comparison between various brands of printer inks is possible for forensic document examination purposes with high degree of certainity as the printer inks are multicomponent, based on the proprietary nature for commercial considerations there is qualitative / quantitative variation, which enables discernation. In this work only qualitative comparative studies were carried out which have given satisfactory results suitable for forensic document examination. Further work is planned by using pattern recognition techniques and quantitative evaluation of each component of the printer inks which could enhance the certainity levels further for the comparison of printer inks. 


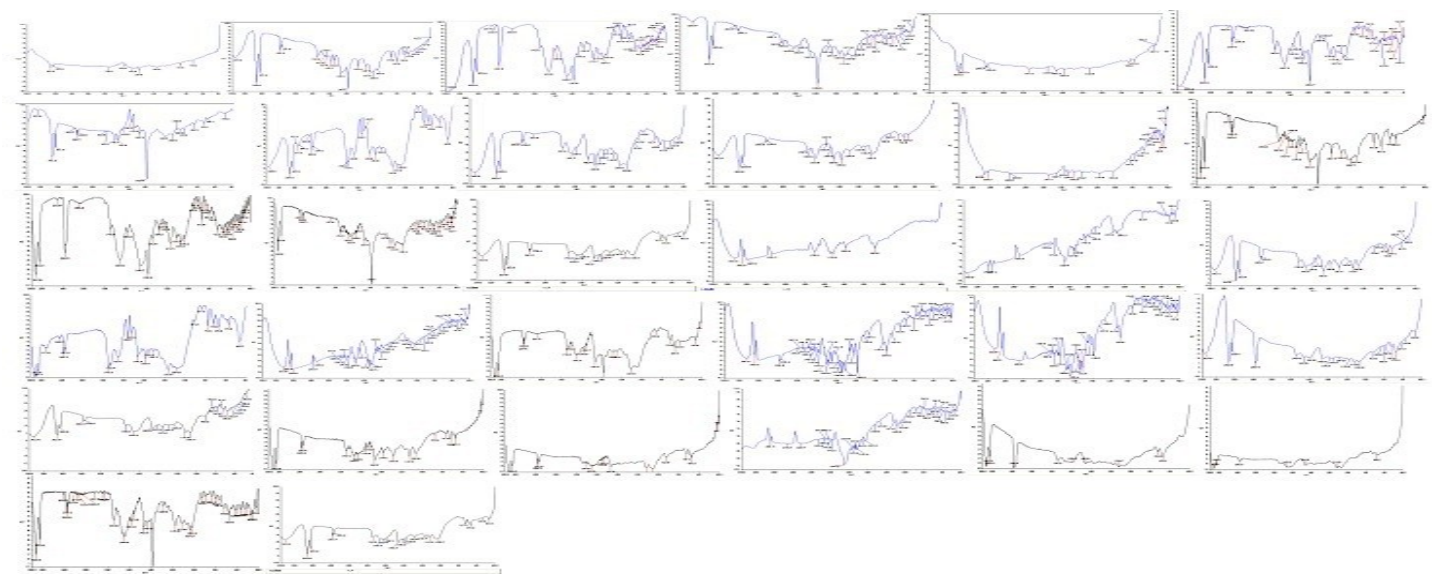

Figure:-2 Typical graphical representation of spectra obtained FT-IR analysis of cyan colour of all four brands.

\section{Conclusion}

The proposed method of infra red spectroscopy, though strictly not nondestructive but it could be used for examination of inks on documents taking extremely small (negligible portion) of the sample from an unimportant area of the document with the permission of the court. Further Pattern recognition techniques could be used which allow forensic examination of ink in short duration of time. The sample preparation technique is simple and the analytical procedure is fast, reproducible and discernable. It is a simple, direct and reproducible method of comparing computer printing inks.

\section{Acknowledgment}

The authors would like to acknowledge the Directorate of Forensic Science Services, MHA, New Delhi for providing financial support for this research work. Thanks are due to Dr.V.K.Goel, Director (Retd.), Forensic Science Laboratory, Delhi for giving instrumental facilities in the laboratory.

\section{References}

[1]. C.W.M. Yuen, S.K.A. Ku, P.S.R. Choi, C.W. Kan and S.Y. Tsang, Determining functional groups of commercially available inkjet printing reactive dyes using infrared spectroscopy. RJTA.9 (2), 2005.

[2]. Huang, C., Analysis and study of the construction of functional polyester fiber, Journal of Textile Research, 25(1), 2004, 30-32.

[3]. Kan C.W., Chan, K. and Yuen C.W.M., Application of low temperature plasma on wool - Part III: Surface Chemical and structural composition, The Nucleus, 37(3-4), 2000, 145-159.

[4]. J.B. Lambert, H.E.Shurvell, D.A. Lightner and R.G. Cooks, Organic Structural Spectroscopy, (N.J.: Prentice-Hall, 1998).

[5]. D.Djozan, T.Baheri, G.Karimian, M. Shahidi, Forensic discrimination of blue ballpoint pen inks based on thin layer chromatography and image analysis, Forensic Science International, 179, 2008, 199-205.

[6]. S.N. Rasool, K.M.Varshney and P Sudhakar. Forensic Examination of ink in inkjet printer cartridges by FT-IR-Micrscopy. The Forensic Scientist OnLine Journal. 7(1-7), 2004.

[7]. P Doherty. Classification of Inkjet Printers and Inks. Journal of the American Society of Questioned Document Examiner. 1(2), 1998, 88-106.

[8]. J. Zimerman, D. Mooney and M.J.Kimmett. Preliminary Examination of Machine Copier Toners by Infrared Spectrophotometry and Pyrolysis Gas Chromatography, Journal of Forensic Science, JFSCA, 31(2), 1986, 489-493.

[9]. R. Chowdry, S.K. Gupta and H.L. Bami. Ink differentiation with IR techniques. Journal of Forensic Science, $18(4), 1973,418$.

[10]. R.A. Merill and E.G. Batrick, Analysis of ball point pen inks by diffuse reflectance infra red spectrometry. Journal of Forensic Science. 37(1-3), 1992, 528-541.

[11]. N. Mizrachi, Z. Aizenshtat, S. Levy and R. Elkayam, Classification and identification of color photocopies by FT-IR and GC/MS. Journal of forensic sciences. 43(2), 1998, 353-361.

[12]. G.S. Kemp and R.N. Totty, The differentiation of toners used in photocopy process by Infrared Spectroscopy. Forensic Science International. 22(1), 1983, 75-83.

[13]. W.D. Mazella, C.J. Lennard and P.A.Margot, Classification and Identification of photocopying toners by Diffuse Reflectance Infrared Fourier Transform Spectroscopy: I Preliminary Results. Journal of Forensic Sciences. 36(2), 1991, 449-465.

[14]. W.D. Mazella, C.J. Lennard and P.A.Margot, Classification and Identification of photocopying toners by Diffuse Reflectance Infrared Fourier Transform Spectroscopy: II Final Report, Journal of forensic sciences.36 (3), 1991, 820-837.

[15]. R.N. Totty, Analysis and differentiation of photocopy toners, Forensic Science Review, 2(1), 1990, 1-23.

[16]. V. Causin, R. Casamassima,C. Marega, P. Maida ,S. Schiavone ,A Marigo and A. Villari, The discrimination potential of Ultraviolet-Visible Spectrophotometry, Thin Layer Chromatography and Fourier Transform Infrared Spectroscopy for the Forensic analysis of black and blue ball point inks, Journal of forensic sciences, 53 (6),2008,1468-1473.

[17]. K. Saini, J. Singh and G.S.Hundal, Thin Layer Chromatography of color Inkjet inks. The Indian Journal of Criminology and Criminalistics, XXVIII. (1), 2007, 74-89.

[18]. RA Merrill, EG Bartick, JH Taylor III, Forensic discrimination of photocopy and printer toners, part I. Anal Bioanal Chem, 376,2003,1272-8.

[19]. RA Merrill, EG Bartick, JH Taylor III, Forensic discrimination of photocopy and printer toners, part II Anal Bioanal Chem, 376,2003, 1279-85. 
[20]. RA Merrill, EG Bartick, JH Taylor III, Forensic discrimination of photocopy and printer toners, part III Anal Bioanal Chem, 376, 2003, 1286-97.

[21]. RA Merrill and EG Bartick, Analysis of ballpoint pen inks by diffuse reflectance infrared spectrometry. Journal of Forensic Sciences, 37,528-541.

[22]. W. Solodar, Designing dyes for inkjet inks" International Journal of Forensic Document Examiners, 4(1), 22-24.

[23]. Brunelle and Crawford, Advances in the forensic analysis and dating of writing ink, $1^{\text {st }}$ Edition,(Springfield, Illinois Charles C Thomas, 2003),113-117.

[24]. J. Zimmerman, D. Mooney and M.J.Kimmett, Preliminary Examination Of Machine Copier Toners by Infrared Spectrophotometry and Pyrolysis Gas Chromatography, Journal of Forensic Sciences , JFSCA, 31(2), 1986, 489-493.

[25]. J. Andrasko, A simple method for sampling photocopy Toners for Examination by Microreflectance Fourier Transform Infrared Spectrophotometry, Journal of Forensic Sciences , JFSCA, 39(1), 1994, 226-230.

[26]. P. Doherty, Classification of Inkjet Printers and Inks, Journal of the American Society of Questioned Document Examiner. 1(2), 1998, 88-106.

[27]. S.N. Rasool, K.M. Varshney and P. Sudhakar, Forensic Examination of Ink in Inkjet Printer cartridges by FTIR-Microscopy," The Forensic Scientist Online Journal,7,2004, 1-7.

[28]. W.D. Mazzella, C.J. Lennard and P.A. Margot, Classification and identification of photocopying Toners by Diffuse Reflectance Infrared Fourier Transform Spectroscopy (DRIFTS): I. Preliminary Results, Journal of Forensic Sciences, JFSCA,1991, 36(2): 449465.

[29]. 29) W.D. Mazzella, C.J. Lennard and P.A. Margot, Classification and identification of photocopying Toners by Diffuse Reflectance Infrared Fourier Transform Spectroscopy (DRIFTS): II. Final Report, Journal of Forensic Science, JFSCA. 36(3), 1991, 820-837.

[30]. 30)M. Szafarska, A. Solarz, R. Wietecha-Poluszny, M. Wozniakiewicz and P. KoscieIniak, Optimization of extraction of inkjet inks from paper for forensic purposes, European Academy of Forensic Science Conference. $5^{\text {TH }}$ Conference EAFS, 2009, QD 05.

[31]. 31) R.L. Williams, Analysis of photocopy toners by infra red spectroscopy, Forensic Science International, 22 (1-3), 1983 , 85-94. 